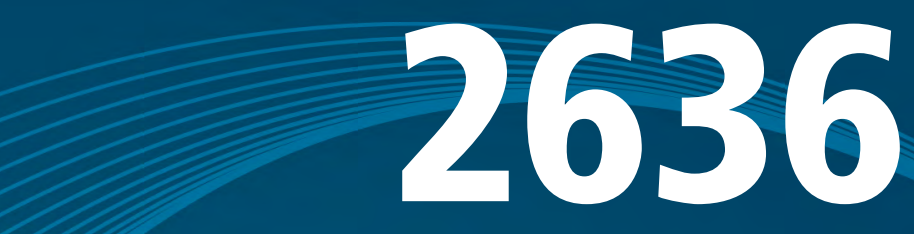

\title{
CRESCIMENTO ECONÔMICO E A ASSOCIAÇÃO ESPACIAL DE CLUSTERS MUNICIPAIS NO ESTADO DE GOIÁS: 2002-2016
}

Antonio Marcos de Queiroz Murilo José de Souza Pires

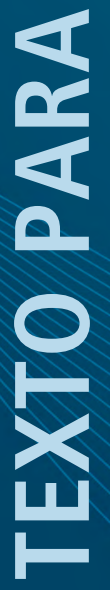





\section{TEXTO PARA DISCUSSÃO}

Brasília, março de 2021

\section{CRESCIMENTO ECONÔIMICO E A ASSOCIAÇÃO ESPACIAL DE CLUSTERS}

\section{MUNICIPAIS NO ESTADO DE GOIÁS: 2002-2016}

Antonio Marcos de Queiroz ${ }^{2}$

Murilo José de Souza Pires

1. Pesquisa interinstitucional realizada entre o Ipea e a Faculdade de Administração, Ciências Contábeis e Ciências Econômicas (Face) da Universidade Federal de Goiás (UFG), conforme estabelecido no Acordo de Cooperação Técnica (ACT) Ipea-UFG no 38/2012, cuja prorrogação foi publicada no Diário Oficial da União, na seção 3, número 129, do dia 7 de julho de 2016.

2. Professor adjunto da Faculdade de Administração, Ciências Contábeis e Ciências Econômicas (Face) da UFG. E-mail: <antonio_marcos_queiroz@ufg.br>.

3. Técnico de planejamento e pesquisa na Diretoria de Estudos e Políticas Regionais, Urbanas e Ambientais (Dirur) do Ipea. E-mail:<murilo.pires@ipea.gov.br>. 


\section{Governo Federal \\ Ministério da Economia \\ Ministro Paulo Guedes}

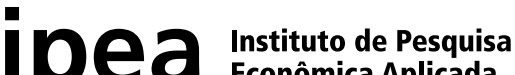 Econômica Aplicada}

Fundação pública vinculada ao Ministério da Economia, o Ipea fornece suporte técnico e institucional às ações governamentais - possibilitando a formulação de inúmeras políticas públicas e programas de desenvolvimento brasileiros - e disponibiliza, para a sociedade, pesquisas e estudos realizados por seus técnicos.

\section{Presidente \\ Carlos von Doellinger}

Diretor de Desenvolvimento Institucional

Manoel Rodrigues Junior

Diretora de Estudos e Políticas do Estado, das Instituições e da Democracia

Flávia de Holanda Schmidt

Diretor de Estudos e Políticas

Macroeconômicas

José Ronaldo de Castro Souza Júnior

Diretor de Estudos e Políticas Regionais, Urbanas e Ambientais

Nilo Luiz Saccaro Júnior

Diretor de Estudos e Políticas Setoriais de Inovação e Infraestrutura

André Tortato Rauen

Diretora de Estudos e Políticas Sociais

Lenita Maria Turchi

Diretor de Estudos e Relações Econômicas

e Políticas Internacionais

Ivan Tiago Machado Oliveira

\section{Assessor-chefe de Imprensa}

e Comunicação (substituto)

João Cláudio Garcia Rodrigues Lima

Ouvidoria: http://www.ipea.gov.br/ouvidoria

URL: http://www.ipea.gov.br

\section{Texto para Discussão}

Publicação seriada que divulga resultados de estudos e pesquisas em desenvolvimento pelo Ipea com o objetivo de fomentar o debate e oferecer subsídios à formulação e avaliação de políticas públicas.

(C) Instituto de Pesquisa Econômica Aplicada - ipea 2021

Texto para discussão / Instituto de Pesquisa Econômica Aplicada.- Brasília : Rio de Janeiro : Ipea, 1990-

ISSN 1415-4765

1.Brasil. 2.Aspectos Econômicos. 3.Aspectos Sociais. I. Instituto de Pesquisa Econômica Aplicada.

CDD 330.908

As publicações do Ipea estão disponíveis para download gratuito nos formatos PDF (todas) e EPUB (livros e periódicos).

Acesse: http://www.ipea.gov.br/portal/publicacoes

As opiniões emitidas nesta publicação são de exclusiva e inteira responsabilidade dos autores, não exprimindo, necessariamente, o ponto de vista do Instituto de Pesquisa Econômica Aplicada ou do Ministério da Economia.

É permitida a reprodução deste texto e dos dados nele contidos, desde que citada a fonte. Reproduções para fins comerciais são proibidas. 


\section{SUMÁRIO}

SINOPSE

ABSTRACT

1 INTRODUÇÃO

.7

2 ALGUNS FATOS ESTILIZADOS DO DEBATE TEÓRICO SOBRE 0 CRESCIMENTO ECONÔMICO.

3 EVIDÊNCIAS EMPÍRICAS: O ESTADO DA ARTE SOBRE O DEBATE SOBRE OS EFEITOS ESPACIAIS DO CRESCIMENTO ECONÔMICO.

4 MÉTODO E PROCEDIMENTOS METODOLÓGICOS

APÊNDICE A 32

APÊNDICE B 34 



\section{SINOPSE}

O objetivo deste texto é analisar o crescimento econômico dos municípios goianos, nos anos de 2002, 2010 e 2016, observando a dependência e a associação espacial em tais municípios. A metodologia contempla a utilização da estatística espacial, especificamente a identificação de autocorrelação dos dados espacialmente, bem como a formação de clusters municipais espaciais. Os resultados apontam que nos clusters alto-alto (AA)/ baixo-baixo (BB) estão os municípios com crescimento do produto interno bruto (PIB) per capita maior/menor do que a média do estado. Estes clusters estáo localizados: i) nas microrregióes do sudoeste de Goiás, em Meia Ponte, no Vale do Rio dos Bois e em Cataláo (clusters AA); e ii) nas microrregiōes de Porangatu, no entorno de Brasília, em Ceres, em Vão do Paranã e na Chapada do Veadeiros (clusters BB). Conclui-se que existe um padrão bastante desigual e heterogêneo no tempo e na distribuição espacial do crescimento econômico em Goiás e que a identificação espacial de clusters de menor taxa de crescimento do PIB per capita permite a elaboração de políticas públicas. Isso faz com que o estado possa atrair novos investimentos na tentativa de mitigar as desigualdades regionais e dinamizar os municípios de baixo crescimento econômico.

Palavras-chave: crescimento econômico; associação espacial; clusters municipais; Goiás.

\section{ABSTRACT}

The objective is to analyze the economic growth of the municipalities in Goiás, in the years 2002, 2010 and 2016, observing the dependence and spatial association in such municipalities. The methodology contemplates the use of spatial statistics, specifically the identification of spatial data autocorrelation, as well as the formation of spatial municipal clusters. The results show that in the high-high/low-low clusters are the municipalities with GDP growth per capita higher/lower than the state average. These clusters are located in the microregions of the Southwest of Goiás, Meia Ponte, Vale do Rio dos Bois and Cataláo (high-high clusters); and in the microregions of Porangatu, Surroundings of Brasília, Ceres, Vão do Paraná and Chapada do Veadeiros (low-low clusters). It is concluded that there is a very uneven and heterogeneous pattern in time and in the spatial distribution of economic growth in Goiás and that the spatial identification of clusters with a lower GDP growth rate per capita allows the elaboration of public policies so that the State can attract new investments in an attempt to mitigate regional inequalities and boost low growth municipalities.

Keywords: economic growth; spatial association; municipal clusters; Goiás. 



\section{INTRODUÇÃO}

Desde o final dos anos 1960, a estrutura agropecuária do estado de Goiás vem passando por um processo de modernização, uma vez que as inovações tecnológicas (físico-químicas, biológicas e mecânicas) introduzidas pela Revolução Verde penetraram as unidades de produção agropecuárias deste espaço regional, impulsionando, assim, o incremento da produção agrícola.

Isso aconteceu por meio dos incentivos proporcionados pelos planos de desenvolvimento regional, como o Programa de Desenvolvimento da Região Centro-Oeste (Polocentro) e o Programa de Cooperação Nipo-Brasileira para o Desenvolvimento dos Cerrados (Prodecer II), que se objetivaram entre os anos de 1974 e 1979, no período do II Plano Nacional de Desenvolvimento (PND), os quais colocaram a região Centro-Oeste na fronteira de expansão da agropecuária nacional.

Neste sentido, a soja tornou-se o principal vetor desse processo de transformação da estrutura produtiva, incrementando, assim, o produto agrícola goiano que proporcionou, nos anos 1980, as condiçóes objetivas para a entrada das grandes tradings companies em Goiás, as quais se estabeleceram na regiáo com o objetivo de demandar parte do excedente agrícola gerado no estado.

Com a crise fiscal e financeira do Estado brasileiro nos anos 1980, o governo federal reduziu os incentivos para o processo de modernização das estruturas produtivas das regióes periféricas como a goiana. No entanto, o estado de Goiás iniciou sua política de incentivo e benefício fiscal com o objetivo de impulsionar o processo de crescimento industrial em seu espaço regional.

Dessarte, o estado de Goiás apresentou, nos anos 1980, um projeto audacioso para impulsionar sua transformação industrial por meio da criação do Fundo de Participação e Fomento do Estado de Goiás (Fomentar), que teve por objetivo internalizar e incrementar parte dos elos dos setores industriais no estado. Entretanto, em 2000, o Fomentar foi substituído pelo Programa de Desenvolvimento Industrial de Goiás (Produzir), que objetivou o fortalecimento das açóes de expansão, a modernização e a diversificação dos setores industriais goianos.

Além disso, o processo de modernização das estruturas produtivas ganhou novo impulso, a partir dos anos 1990, quando o estado de Goiás foi incorporado, via Eixos Nacionais de Integração e Desenvolvimento (Enid), as cadeias produtivas integradas aos mercados internacionais. Assim, a expansão da agropecuária que se desenvolveu em 
meio à agricultura cientifica globalizada, que além dos mecanismos de financiamento privados proporcionados pelo capital financeiro, ${ }^{1}$ teve também incentivos do Estado por meio dos programas de incentivo fiscal, créditos provenientes do Banco Nacional de Desenvolvimento Econômico e Social (BNDES), como também do Banco do Brasil, que é a instituição responsável pelo repasse dos recursos do Fundo Constitucional do Centro-Oeste (FCO).

Tudo isso teve um papel importante para incrementar o crescimento do produto goiano no contexto nacional e internacional. Segundo dados de IMB (2018), em 2017, Goiás esteve na quarta posição entre os principais estados produtores de grãos no Brasil, perdendo somente para os estados de Mato Grosso, Paraná e Rio Grande do Sul. No caso do etanol, Goiás apresentou-se na segunda posição, atrás apenas do estado de São Paulo.

Entretanto, quando se observa a remuneração média, em 2016, o estado de Goiás encontrou-se na 16 ${ }^{\mathrm{a}}$ posição, ficando atrás de estados como, por exemplo: Mato Grosso, na sexta posição; Mato Grosso do Sul, na décima posição; Tocantins, na 13 a posiçãa; e, por fim, o estado do Pará, na $14^{\underline{a}}$ posição. Em termos de indicadores sintéticos, o estado de Goiás esteve na nona colocação do Índice de Desenvolvimento Humano (IDH) de 2000. Em 2015, o estado ocupou a décima colocação, permanecendo, deste modo, atrás de Unidades da Federação (UFs) como: Distrito Federal, São Paulo, Santa Catarina, Paraná, Rio de Janeiro, Rio Grande do Sul, Espírito Santo, Minas Gerais e Mato Grosso.

Esses dados apontam que estilo de desenvolvimento do estado de Goiás primou pela estratégia de modernização da estrutura produtiva, incrementando, por conseguinte, o produto per capita, porém, com fortes indícios que reforçaram a heterogeneidade estrutural produtiva no estado. ${ }^{2}$ Isto é, o padrão de reprodução do capital no estado de Goiás se assenta em uma estrutura espacial e produtiva, marcada por uma heterogeneidade típica de uma economia periférica como a brasileira. É em meio a esta problemática que se apresenta a proposta deste trabalho, ou seja, buscando identificar em que medida o crescimento econômico vivenciado no estado de Goiás determinou o padrão de distribuição espacial do produto interno bruto (PIB) per capita dos municípios goianos nos anos de 2000, 2010 e 2016.

1. Como apontou Samuel (2018, p. 13):

0 início do século XXI marcou a chegada de uma nova safra de capitalistas na agricultura mundial. Trata-se da presença do capital financeiro, representado por diversos tipos de fundos (pensão, soberanos, hedge, endowments, private equity), corporações (bancos, seguradoras e empresas) e indivíduos de alta renda, sobretudo, nos países de maior produção agrícola e com dinâmicas de fronteira como o Brasil.

2. Para maiores detalhes veja Pires (2016). 
Para tanto, a hipótese deste texto encontra-se alicerçada nas premissas teóricas de Myrdal (1965), Perroux (1977) e Hirschman (1977) que destacaram, em um sentido mais amplo, que o processo de crescimento econômico náo se objetiva de forma homogênea no espaço e no tempo, uma vez que, fatores econômicos, quando acionados pelas decisóes de investimentos, se materializam de forma heterogênea no espaço regional ocasionando, assim, um crescimento desequilibrado entre os espaços regionais.

Desse modo, essa pesquisa justifica-se em várias dimensões. Quanto à relevância da temática, o debate sobre a problemática e os impactos do crescimento econômico na distribuição espacial municipal têm suma importância para se verificar se há ou não concentração da atividade econômica em certos municípios ou se os seus efeitos estão sendo distribuídos de forma homogênea no espaço regional. Além disso, a compreensão se há ou não a concentração produtiva nos municípios mais ricos em detrimento aos municípios mais pobres, tornando-se um importante elemento para subsidiar as discussões de políticas públicas para o desenvolvimento inter-regional goiano.

Por sua vez, é importante ressaltar que o método adotado para fazer a identificação da existência de dependência e de associação de clusters espaciais é o índice de Moran global e local, dos diagramas de dispersão e da existência de clusters espaciais. Para tanto, as variáveis adotadas na investigação foram extraídas nos bancos de dados do Instituto Brasileiro de Geografia e Estatística (IBGE) e do Ipea.

Por fim, os valores nominais do PIB per capita municipal foram deflacionados pelo deflator implícito, o qual transformou os valores correntes em valores constantes de 2010, para o primeiro período, entre 2002 e 2010; e valores constantes de 2016, para o segundo período entre 2010 e $2016 .{ }^{3}$ Ressalta-se que o deflator implícito é proveniente da razão entre o cálculo da variação do valor adicionado bruto (VAB) do estado de Goiás entre os períodos de 2002 a 2010 e de 2010 a 2016 e do cálculo da variação do índice de volume de Goiás para os períodos destacados. ${ }^{4}$

Para tanto, o trabalho está estruturado em quatro seçóes, além da introdução e das consideraçôes finais. Na segunda seção, o objetivo é apresentar de forma sucinta o debate teórico existente sobre o crescimento econômico, porém priorizando alguns fatos estilizados. A terceira seção do trabalho procura apresentar algumas evidências empíricas do estado da arte que contempla o debate sobre os efeitos espaciais do crescimento

3. Adotou-se este procedimento porque não há cálculo da taxa de crescimento Inter períodos.

4. Veja maiores detalhes no apêndice $B$. 
econômico. Na quarta seção, destaca-se o método e os procedimentos metodológicos. $\mathrm{Na}$ quinta seção, são apresentados os resultados da pesquisa, como também, sua discussão.

\section{ALGUNS FATOS ESTILIZADOS DO DEBATE TEÓRICO SOBRE O CRESCIMENTO ECONÔMICO}

Em uma visão mais ampla, os clássicos defendiam a ideia de que o crescimento econômico era função da renda ex-ante. Tal função proporcionava um nível de poupança que financiava os investimentos produtivos, acelerando, desta forma, o processo de acumulação de capital que se objetivava no incremento do produto total per capita. $\mathrm{Na}$ obra Riqueza das Naçôes, Smith defende que o crescimento econômico tem como causa principal a divisão social do trabalho, uma vez que a fragmentação do processo de produção em várias etapas acaba impulsionando a especialização deste trabalhador em um ponto especifico do processo de trabalho, melhorando suas habilidades e capacidades técnicas que acabam incrementando, por conseguinte, a produção total por trabalhador.

Por este ângulo, Smith compreende que a ordem natural da sociedade passa pela liberdade dos mercados, a qual é a melhor forma para se alocar os fatores de produção, ou seja, capital e trabalho em seu nível ótimo, como também proporciona um ambiente de igualdade de oportunidades entre os agentes econômicos. Desse modo, os mercados em crescimento geram elevação da renda e do emprego e, consequentemente, haverá um número maior de trabalhadores produtivos em relação aos improdutivos, gerando elevação da renda nacional pela maior empregabilidade da mão de obra (Souza, 1999; Vieira, 2009; Dassow, Costa e Figueiredo, 2012).

Neste sentido, Smith foi o precursor, no campo econômico, da ideia que o mercado é o meio natural para se organizar a sociedade. No entanto, era preciso compreender um pouco mais sobre os determinantes que impulsionavam o crescimento do produto per capita de um país. Com isso, o modelo de Harrod-Domar, criado nos anos 1930 e 1940, foi considerado o primeiro modelo de crescimento exógeno com elementos pós-keynesianos e tinha por objetivo identificar que o crescimento econômico depende do nível de poupança e da produtividade do capital.

Por sua vez, o trabalho de Solow (1956), intitulado A contribution to the theory of economic growth, tornou-se referência na literatura sobre o tema, porque fez uma teorização do crescimento econômico, mas em uma perspectiva de uma economia desenvolvida, na qual sua estrutura econômica não apresentava sérias clivagens decorrentes da propagação de forma assimétrica do progresso técnico entre os agentes econômicos 
no tempo. Além disso, esse modelo analítico encontrava-se dentro dos postulados da escola neoclássica que fazia uma crítica aos modelos de crescimento keynesianos de Harrod-Domar (Bastos e Britto, 2010).

Por sua vez, os modelos Harrod-Domar e Solow foram construídos para explicarem os determinantes do crescimento em economias centrais tendo, assim, pouco a dizer sobre economias duais, ou melhor, que apresentavam, no mesmo espaço e tempo, um lado moderno e outro atrasado como aquelas existentes na periferia do capitalismo mundial. Quer dizer, precisava-se desenvolver evidências teóricas que conseguissem explicar fenômenos econômicos que retratassem economias que se mantinham em um nível de baixo crescimento e estruturas econômicas marcadas por uma heterogeneidade, na qual o moderno e o atrasado se entrelaçavam no mesmo tecido produtivo.

Essa diferenciaçáo é importante porque destaca que esses países apresentam características de abundância do fator trabalho, de escassez de capital físico, de baixa taxa de poupança e, consequente, baixa renda média. Como consequência, essas características reduzem a capacidade de acumulação de capital, mantendo o país em um baixo nível de crescimento (Sato, 1964).

Para a tradição clássica, o trabalho de Lewis (1954), intitulado $O$ desenvolvimento econômico com oferta ilimitada de mão de obra, fez uma leitura do crescimento econômico, mas em uma perspectiva estrutural diferente de Solow (1956), uma vez que, Lewis (1954) destacou que certas economias eram marcadas por uma dualidade estrutural, na qual o moderno e o atrasado conviviam no período ex-ante da convergência estrutural. Nessa perceptiva, o trabalho de Lewis (1954) “(...) considera explicitamente que a abordagem neoclássica é inadequada para a teoria do desenvolvimento” (Bastos e Britto, 2010, p. 13), haja vista que, a hipótese de trabalho neoclássica é de que a estrutura econômica é homogênea, ao passo que, para Lewis (1954) é heterogênea, retratando, por conseguinte, melhor as estruturas das economias periféricas.

Assim, o trabalho de Perroux (1977) partiu da premissa de que a estrutura produtiva em que se materializa o desenvolvimento econômico de uma regiáo é marcada por uma heterogeneidade estrutural, visto que não acontece de forma homogênea entre as regiôes. Para tanto, Perroux (1977) enfatizou o papel que as inovaçóes ${ }^{5}$ desempenham para a constituição dos polos de crescimento, que são elementos singulares no processo de desenvolvimento desigual com forte identificação geográfica.

5. 0 conceito de inovação adotado por Perroux (1977), em sua análise sobre a formação dos complexos industriais, assume algumas diferenças em relação à abordagem schumpeteriana. Para ele, deve-se considerar três elementos importantes em tais complexos: a indústria-chave, o regime não-concorrencial do complexo e a questão da aglomeração territorial. 
Para ele, a internalização dos setores industriais em um espaço regional tem um papel singular no processo de desenvolvimento, visto que a indústria tem uma influência desestabilizante na geração de ondas de inovaçôes. Desta forma, o crescimento econômico não ocorre de forma uniforme no tempo e no espaço (crescimento desequilibrado), mas se intensifica em determinadas regiôes, devido à existência de indústrias motrizes ou indústrias-chave, dentro de um processo de encadeamento para trás e para frente (indústrias correlatas e secundárias), que proporciona uma elevação da produçáo local e em regióes vizinhas, bem como a formação de polos de crescimento, além de uma constante alteração na estrutura econômica, social e cultural de uma determinada região (Perroux, 1977).

Nesta lógica, o trabalho de Hirschman (1977) destaca que o dinamismo econômico e a atração de indústrias motrizes seguem, em linhas gerais, as ideias apresentadas por Perroux (1977); contudo, enfatiza a importância do papel do Estado na promoçáo do crescimento e do desenvolvimento. Para ele, isso se daria pela alocaçáo dos investimentos públicos (por exemplo, infraestrutura e disponibilidade de crédito), mostrando-se bastante óbvia pela qual uma política econômica influencia o crescimento de diversas regiôes de um determinado país.

Dessarte, há três padrōes de alocação dos fatores de produçáo no espaço que foram caracterizados como: i) dispersão; ii) concentração em áreas de crescimento; e iii) tentativa de promoção do desenvolvimento de áreas consideradas atrasadas. A dispersão dos investimentos é bastante comum em países subdesenvolvidos pela grande quantidade de pequenos projetos, já que requer capacidade tecnológica e de planejamento relativamente pequena. Por seu turno, a concentraçáo de investimentos públicos em áreas de crescimento náo é considerada pelo autor como satisfatória ao longo prazo, pelos governos, devido à referência de igualdade e coesão nacional.

Por fim, o investimento em áreas atrasadas poderia ser canalizado em grande escala, porém com o risco de ser mal orientado devido às intençóes políticas locais. Embora tal canalizaçáo possa ser realizada de áreas de alto crescimento para as áreas atrasadas, estagnadas, ao mesmo tempo, que poderia também ser oriunda de impostos e outros mecanismos de aumento da receita (Hirschman, 1977).

Por outro lado, Myrdal (1965) não acredita na canalização dos investimentos para as áreas atrasadas e estagnadas, embora reconheça que exista um processo de aglomeração de forma desigual. Ele identifica o chamado "princípio da causação circular cumulativa”, pelo processo de aglomeraçáo que atrai novos elementos que retroalimentam o 
processo por meio da continuidade. Entretanto, as regióes ricas continuariam mais ricas com este processo, enquanto as mais pobres, tenderiam a permanecer pobres, com o que ele chamou de círculo vicioso da pobreza e, consequentemente, a manutenção do desenvolvimento desigual, já que ele considera como desequilibrado.

Assim, estes pensadores econômicos defendem a tese que o crescimento econômico não se objetiva de forma homogênea no tempo e no espaço territorial, uma vez que negam os postulados teóricos ortodoxos da convergência das trajetórias de crescimento das regióes, quer dizer, o estilo de desenvolvimento de uma região não segue o receituário apresentado por Rostow (2010) de etapas de desenvolvimento. Ou seja, não há uma linearidade que desloca uma região da condição de subdesenvolvida para uma condição de desenvolvida segundo a lógica da razão expressa: i) na passagem da sociedade tradicional; para ii) a sociedade que criou as pré-condiçóes para a decolagem; para iii) a sociedade da decolagem; para em seguida atingir iv) a marcha para a maturidade; e, por fim, v) a sociedade de massas.

A premissa fundamental que sustenta a lógica de acumulação de capital em uma economia periférica é que ela é marcada profundamente por uma estrutura econômica dual, na qual o moderno e o atrasado convivem como irmáos siameses, no mesmo espaço e tempo, uma vez que "o subdesenvolvimento não constitui uma etapa necessária do processo de formação das economias capitalistas modernas. É em si, um processo particular, resultante da penetração de empresas capitalistas modernas em estruturas arcaicas" (Furtado, 1964, p. 184). Para os autores citados, existem fatores econômicos que, ao serem impulsionados, determinam trajetórias diferenciadas de crescimento que acabam reforçando os desequilíbrios regionais e estruturais de uma economia.

\section{EVIDÊNCIAS EMPÍRICAS: O ESTADO DA ARTE SOBRE O DEBATE SOBRE OS EFEITOS ESPACIAIS DO CRESCIMENTO ECONÔMICO}

Para se compreender um pouco mais sobre o processo de distribuição espacial da atividade econômica se faz, nesta seção do trabalho, um levantamento de algumas investigaçóes que tem por fito apresentar evidências empíricas que discutem os impactos do crescimento econômico em algumas regióes brasileiras. Para tanto, o trabalho empírico de Barreto et al. (2010) busca identificar as mudanças ocorridas na distribuição espacial da atividade econômica no estado do Ceará no período de 1996 a 2003. Os autores utilizaram a econometria espacial na verificação da evolução dos clusters e estimaram a 
convergência absoluta do PIB per capita ao longo do período analisado. Os resultados apontam a existência de efeitos espaciais relevantes e o relacionamento entre os municípios e a formaçáo de clusters importantes no interior do estado, embora as diferenças regionais continuem elevadas.

No caso de Dassow, Costa e Figueiredo (2012), o trabalho teve por objetivo analisar o crescimento econômico municipal no Mato Grosso entre 2001 e 2007, porém usando a estatística espacial de Moran, os mapas de dispersão e a análise de clusters de crescimento econômico. Eles apontam que há pequenos efeitos espaciais nas taxas de crescimento e renda per capita e também identificam a formação de clusters de crescimento econômico no estado.

Em um estudo mais amplo para o Brasil, Lima e Lima (2016) analisaram a distribuição espacial do PIB per capita nas microrregióes brasileiras no período de 1970 a 2012, por meio das técnicas de análise exploratória espacial. Os resultados apontam que a distribuiçấo espacial do PIB per capita permaneceu estável durante todo o período, pois cerca de $82 \%$ das microrregióes que se localizavam em um cluster de pobreza, em 1970, permaneceram, em 2012, com a continuidade da situaçáo de baixo crescimento do produto.

Numa perspectiva setorial, Silva, Souza e Martins (2012), por meio da análise espacial, identificaram padróes de associaçáo espacial de clusters municipais com maior participaçáo do PIB agropecuário de Minas Gerais entre 1996 e 2006. Os resultados revelam que a distribuição espacial da produção agrícola está concentrada nos municípios com maior produção, localizados no oeste do estado, e que houve uma redução da especialização agropecuária nestes municípios, resultando na importância da interação do agronegócio com os demais setores daqueles municípios.

\section{MÉTODO E PROCEDIMENTOS METODOLÓGICOS}

A metodologia deste trabalho está baseada na análise exploratória dos dados espaciais (Aede), cujo objetivo é identificar a existência de dependência e de associação de clusters espaciais do crescimento econômico municipal em Goiás para os anos de 2002, 2010 e 2016, considerando a dependência espacial contígua das características municipais de similaridade e de dissimilaridade, com a utilizaçáo do índice de Moran global e local, dos diagramas de dispersão e da existência de clusters espaciais. 
É necessário capturar a relação de espacialização entre todos os pares de localização existentes (municípios), com a utilizaçáo de uma matriz de estrutura espacial ou matriz de pesos espacial W (Weight). Cada valor $w_{i j}$ vai depender da relaçáo espacial entre as localidades $i$ e $j$. Vários critérios são usados para atribuir valores a cada elemento da matriz, os mais comuns são: critério da distância, critério da adjacência e critério da vizinhança, todos eles assumindo $w_{i j}=1$ se os elementos compartilham de distância, similaridade e proximidade, caso contrário, $w_{i j}=0$ (Câmara et al., 2002).

O ponto de partida para a análise baseia-se na primeira lei da geografia - lei de Tobler -, de que "Tudo depende de todo o restante, mas o que está mais próximo, depende mais (...)". Parte-se da mensuração da autocorrelação espacial entre diversas variáveis consideradas relevantes (Anselin, 1995; Almeida, 2012).

Moran (1948), citado por Almeida (2012), utilizou um coeficiente de autocorrelação espacial, por meio da medida de autocovariância como produto cruzado, com a matriz de ponderação espacial normalizada na linha. A estatística $I$ de Moran pode ser expressa na equação (1). O cálculo pode ser realizado pelo índice de Moran global, que varia entre -1 e +1 em relaçáo ao valor esperado da hipótese nula $\left(h_{0}\right)$, que considera o efeito da aleatoriedade dos dados no espaço, isto é, não existe dependência espacial entre eles.

$$
I=\frac{n}{\sum \sum w_{i j}} \frac{\sum \sum w_{i j}\left(y_{i}-\bar{y}\right)\left(y_{j}-\bar{y}\right)}{\sum\left(y_{i}-\bar{y}\right)^{2}} .
$$

Em que $n$ corresponde ao número de unidades espaciais; $y$ é o valor do atributo em cada área observada, ou variável de interesse; $\bar{y}$ é o valor médio do atributo na região de estudo; $i$ e $j$ designam os municípios distintos onde há observação dessa mesma variável $y$; os valores atribuídos a um determinado município (i) dependem dos valores dos vizinhos imediatos $(j)$, de modo que se estabelece um grau de interação dos distintos municípios $i$ e $j$. O termo $w_{i j}$ é o critério de vizinhança (operador de defasagem espacial) estabelecido para dois municípios distintos, que compóe a matriz $W$ de peso dos municípios $i$ e $j$, conforme Scrucca (2005), Almeida (2004; 2012) e Bachi e Caldarelli (2015).

Além da análise do índice de Moran global, o indicador de $I$ de Moran local pode ser usado para identificar localmente os efeitos espaciais de autocorrelação. Este indicador é oriundo da decomposição do indicador global de autocorrelação na contribuição local de cada observação em quatro categorias, cada uma de forma individual, o que corresponde a um quadrante no diagrama de dispersão de Moran. Ademais, a 
interpretação de $I$ Moran local revela a indicação do grau de agrupamento dos valores por similaridade em relação a uma determinada observação (município, região, estado, país etc.), resultando na identificação de clusters espaciais considerados significantes estatisticamente. A equação (2) pode ser formalizada como:

$$
I_{i}=\frac{\left(y_{i}-\overline{y_{i}}\right) \sum w_{i j}\left(y_{j}-\overline{y_{i}}\right)}{\sum\left(y_{i}-\bar{y}\right)^{2} / n}=Z_{i} \sum w_{i j} z_{j},
$$

em que $n$ corresponde ao número de áreas ou polígonos (municípios); $y_{i}$ é o valor do atributo considerado no município $i ; \bar{y}$ representa o valor médio do atributo na região de estudo; e $w_{i j}$ são os pesos atribuídos conforme a conexão entre os municípios $i$ e $j$.

Os termos $z_{i}$ e $z_{j}$ são considerados como variáveis padronizadas, enquanto a soma sobre a variável $y$ indica que somente os vizinhos diretos de um determinado município $i$, atendendo assim o sentido de ser local (Anselin, 1995). Nesse caso, a estatística demonstra a significância do agrupamento existente em determinado local decompondo o indicador global em quatro tipos de padróes de associação local. O I de Moran local indica o grau de associação existente entre o valor de uma variável $y_{i}$ em um determinado local e a média da variável nos municípios vizinhos (Anselin, 2003).

O valor esperado da estatística $E\left[I_{i}\right]$ sob a hipótese de aleatoriedade é dado pela equação (3):

$$
E\left[I_{i}\right]=-\frac{w_{i}}{(n-1)},
$$

em que $w_{i}$ é o somatório dos elementos da linha e $n$ o número de regióes. Se $\mathrm{I}>\mathrm{E}[I]$ a autocorrelação é positiva com similaridade, ou seja, se $\left(y_{j}-\bar{y}\right)>0$, então $y_{i}$ representa um hot spot (concentração). Se $I<\mathrm{E}[I]$, a autocorrelação é negativa, ou seja, se $\left(y_{j}-\bar{y}\right)<0$, então diz-se que a região $y_{i}$ representa um cold spot (dispersão) (Anselin, 1995; Scrucca, 2005; Almeida, 2012).

Os valores do I de Moran univariado e/ou bivariado também podem ser usados para mapear os clusters em quatro quadrantes: alto-alto (AA), baixo-baixo (BB), baixo-alto (BA) e alto-baixo (AB). No primeiro, estão os valores acima da média chamado de AA (high-high); o terceiro mostra os valores das localidades com valores abaixo da média, chamado de BB (low-low), ou seja, quadrantes com autocorrelação positiva, com características similares. Os segundo e quarto quadrantes são aqueles em que apresentam 
valores dissimilares, BA (low-high) e AB (high-low), ou seja, localidades consideradas ilhas com baixa autocorrelação espacial, próximas de zero - eixo central (Anselin, 2003).

$\mathrm{Na}$ estatística espacial utilizou-se a convenção de contiguidade "rainha" para definir a vizinhança entre dois municípios, considerando a fronteira geográfica e os vértices contíguos. Assim, optou-se pelo uso de matriz do tipo binária, a partir da ideia de contiguidade, sendo determinados os municípios que dividem a mesma fronteira geográfica e também de valores próximos para alguma variável em questão.

Dessa maneira, foi possível identificar as coordenadas geográficas dos municípios adotando tipologia matricial binária, valor um, quando há relação de vizinhança, e valor zero, sem contiguidade. As coordenadas geográficas dos municípios foram coletadas no site do IBGE para a elaboração dos mapas de clusters espaciais no estado de Goiás.

O tratamento dos dados contemplou a análise no âmbito municipal em cross-section (período 2002, 2010 e 2016) com o auxílio do software Geoda para cálculo dos índices de Moran global e local, além da identificação dos mapas de clusters univariados. Para análise, escolha do ano de 2002 é justificada por ser o início de uma série contínua do IBGE para o VAB (elaboração dos índices de VAB e de volume).

Foram utilizadas as fontes de pesquisa de dados (quadro 1): contas nacionais, do IBGE, e contas regionais, do Ipea.

QUADRO 1

Variáveis utilizadas

\begin{tabular}{lcc}
\hline Variáveis & Sigla & Fonte \\
\hline Taxa de crescimento do PIB per capita 2002-2010. & tx_pibph & IBGE \\
Taxa de crescimento do PIB per capita 2010-2016. & tx_pibph & IBGE \\
PIB municipal per capita, 2002, 2010 e 2016. & Pibph & IBGE/lpea \\
\hline
\end{tabular}

Fonte: Elaboração própria com dados do IBGE ([s.d.]) e Ipea ([s.d.]).

A estatística Local Indicator of Spatial Association (LISA) deve satisfazer a dois critérios: i) a capacidade de indicar clusters espaciais significativos estatisticamente para cada observação; e ii) o somatório dos indicadores locais é proporcional ao indicador de autocorrelação espacial global para todas as regióes (Anselin, 1995). Ademais, o índice de Moran local faz uma decomposição do índice global para uma variável padronizada, sendo, portanto, o Moran local atende aos critérios para o indicador LISA. 
No caso da análise deste estudo, o índice de Moran local pôde identificar quais são os municípios com maior e menor potencial de crescimento econômico (clusters espaciais), por meio da variável econômica (PIB per capita municipal), bem como as suas respectivas taxas de crescimento entre os anos supracitados.

Nos diagramas de dispersão, o cálculo da composição do percentual dos municípios em cada quadrante foi realizado em relação ao total de 246 municípios. Além disso, foi realizado o cálculo das médias percentuais da taxa de crescimento do PIB per capita, obedecendo a composição dos municípios em cada cluster AA, BB, AB e BA, em relação ao estado de Goiás nos períodos de 2002 a 2010 e de 2010 a 2016.

\section{RESULTADOS E DISCUSSÃO}

\section{1 Índice de Moran global e autocorrelação espacial}

Com o objetivo de identificar a dependência/associação, bem como a autocorrelaçáo espacial do crescimento econômico municipal em Goiás, por meio das taxas de crescimento do PIB per capita, o ponto de partida é o da Aede. A tabela 2 apresenta os resultados da estatística $I$ de Moran global, relembrando que tal índice mensura a associação espacial global pela autocorrelação positiva/negativa dos valores entre -1 e +1 .

Ao analisar o $I$ de Moran, verifica-se a relativa evidência de autocorrelação espacial positiva em Goiás, pois todas as variáveis analisadas apresentam valores maiores que $\mathrm{E}(\mathrm{I})=-0,004$, significando não aleatoriedade espacial dos dados, conforme mostrado por Anselin (1995; 2003) e Almeida (2012) na etapa da metodologia. Ou seja, o índice de Moran é maior para o PIB per capita nos anos de 2002, 2010 e 2016, com maior autocorrelação espacial. Para a taxa de crescimento do PIB (2002-2010 e 2010-2016), a autocorrelação espacial global é baixa entre os municípios, sendo os resultados com significância estatística de 0,05 .

TABELA 2

Índice de Moran global, teste de autocorrelação espacial (2002, 2010 e 2016)

\begin{tabular}{lcccc}
\hline Variável & Ano & I de Moran & $E(I)$ & p-valor \\
\hline \multirow{2}{*}{ Taxa de crescimento PIB per capita } & $2002-2010$ & $-0,0180$ & $-0,004$ & 0,000 \\
& $2010-2016$ & 0,0060 & $-0,004$ & 0,000 \\
PIB per capita & 2002 & 0,1550 & $-0,004$ & 0,000 \\
& 2010 & 0,1270 & $-0,004$ & 0,000 \\
& 2016 & 0,3080 & $-0,004$ & 0,000 \\
\hline
\end{tabular}

Fonte: Resultados da pesquisa. 
A análise do diagrama de dispersão relaciona uma variável univariada (eixo horizontal) e sua defasagem espacial (eixo vertical) da taxa de crescimento do PIB per capita descritas no gráfico 1A, 2002-2010; e no gráfico 1B, 2010-2016. Em ambos os períodos, o índice de Moran global se aproximou de zero), portanto, pode-se inferir que não há autocorrelação espacial entre os dados para os períodos supracitados, $\mathrm{I}=-0,018 \mathrm{e}$ $\mathrm{I}=0,060$, respectivamente.

\section{GRÁFICO 1}

Diagramas de dispersão de Moran da taxa de crescimento do PIB per capita (2002-2010 e 2010-2016)

$1 \mathrm{~A}-2002$ a 2010
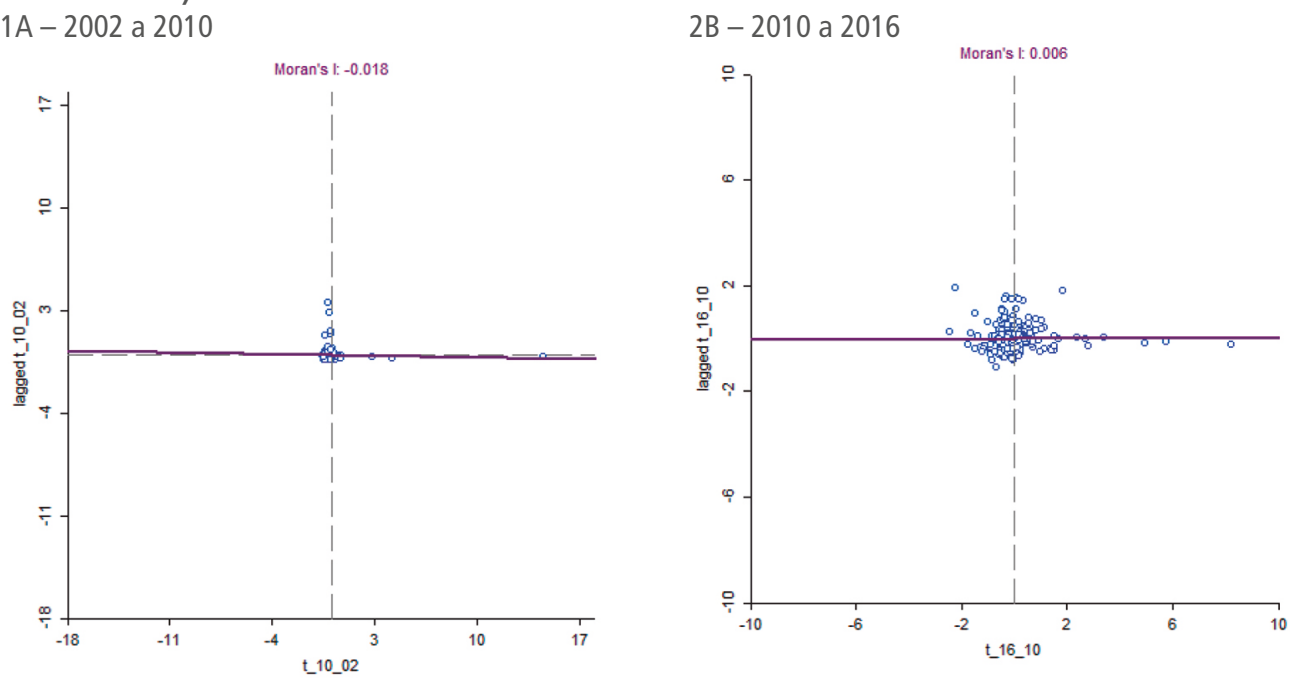

Fonte: Resultados da pesquisa.

Entretanto, ao analisar cada ano separadamente (gráfico 2), os diagramas de dispersão de Moran do PIB per capita para os anos 2002, 2010 e 2016 revelam que o índice de Moran global no período supracitado passa de $\mathrm{I}=0,155$, para $\mathrm{I}=0,127 \mathrm{e}$, por fim, $\mathrm{I}=0,308$, respectivamente. 
GRÁFICO 2

Diagramas de dispersão de Moran do PIB per capita (2002, 2010 e 2016)

$2 \mathrm{~A}-2002$
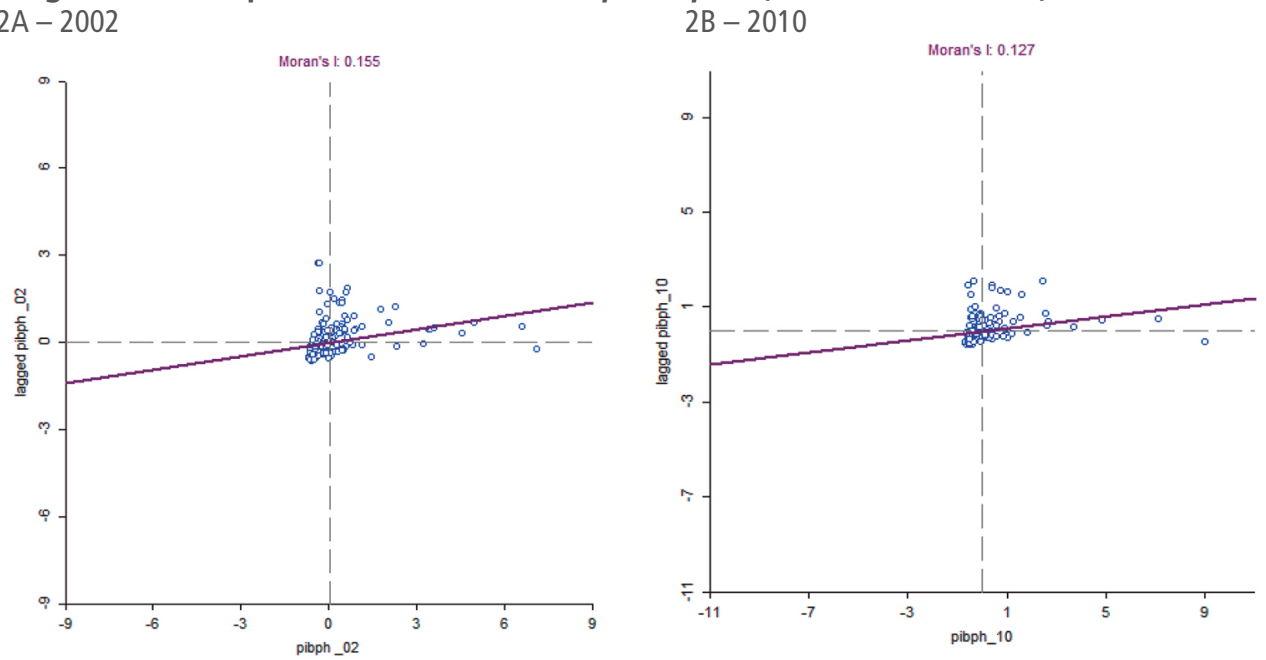

$2 C-2016$

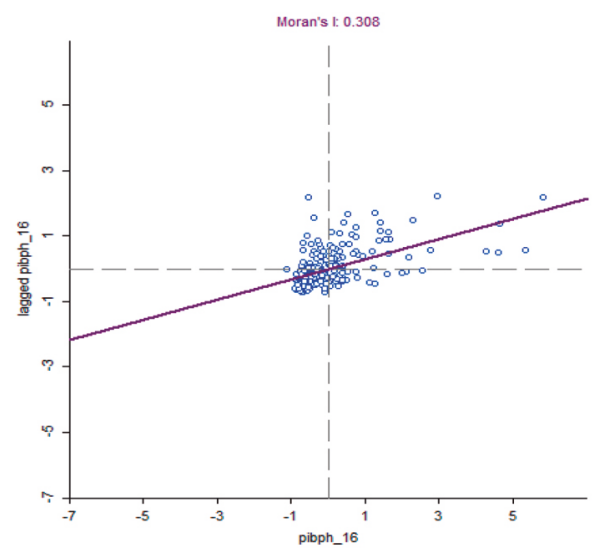

Fonte: Resultados da pesquisa.

Estes dados indicam que, entre 2002 e 2010, houve uma queda da dependência espacial nos municípios e, em 2016, entretanto, aumentou novamente a dependência espacial dos dados e também a autocorrelação positiva, pois municípios com elevado PIB per capita são contíguos de municípios com as mesmas características nos primeiros e terceiros quadrantes AA e BB. A principal hipótese para a queda do índice de Moran global é de que a crise de 2008 tenha impactado as economias nos municípios e, consequentemente, a redução do PIB per capita. 
Se comparar o nível de concentração dos municípios nos quadrantes, em termos percentuais, nos três anos (2002, 2010 e 2016), houve tendência de crescimento do PIB per capita, embora a maioria dos municípios tenha apresentado valores localizados no quadrante $\mathrm{BB}$ (baixo crescimento do PIB per capita e baixo crescimento do PIB per capita defasado), 54,87\%, 50,40\% e 53,66\%, respectivamente. Nesse mesmo período, o quadrante AA passa de $18,31 \%$ para leve melhora de $20,73 \%$ e passa a melhorar com o percentual de $21,54 \%$. Por seu turno, o quadrante $A B$ passa de $9,75 \%$ para $14,22 \%$ e $9,35 \%$, respectivamente. O quadrante BA passa de $14,63 \%$ para $17,07 \%$ e para $15,45 \%$, respectivamente.

Pode-se concluir que a maior parte dos municípios goianos apresenta baixo PIB per capita e são circunvizinhos de outros municípios que apresentam características semelhantes, apesar da estabilidade do PIB per capita em 2016 no quadrante AA, alto crescimento e alto crescimento defasado.

\subsection{Clusters da taxa de crescimento do PIB per capita}

O mapa 1A apresenta o mapa de clusters da estatística LISA da taxa de crescimento do PIB per capita entre 2002 e 2010, com valores estatisticamente significativos (apêndice A, mapa A.1A). Nesse período observa-se que há formaçáo de clusters de crescimento econômico do tipo $\mathrm{AA}$, do tipo $\mathrm{BB}$, do tipo $\mathrm{BA}$ e do tipo $\mathrm{AB}$. Esta análise, ao contrário do índice de moral global, permite identificar localmente, em quais municípios ocorreram ou não o crescimento econômico.

Especificamente o foco de análise nesta etapa se concentra principalmente nos municípios localizados nos clusters $\mathrm{AA}$ de cor vermelha e $\mathrm{BB}$ de cor azul, pois apresentam altas/baixas taxas de crescimento econômico e tem contiguidade com municípios com as mesmas caraterísticas.

Nesse período, o cluster AA apresenta apenas um município - Colinas do Sul (nordeste goiano) - com taxa média de crescimento entre 2002 e 2010 de 42,73\% e taxa anual de 4,03\% ao ano (a.a.), enquanto a média do estado de Goiás no mesmo período foi de $25,38 \%$ e $2,55 \%$ a.a. Ao contrário do cluster $\mathrm{AA}$, o cluster $\mathrm{BB}$, em cor azul, é composto por dezesseis municípios e apresenta uma média de crescimento do PIB per capita de apenas 1,05\%, taxa média anual de crescimento no período de $0,12 \%$ a.a., considerando o PIB per capita deflacionado. Tais municípios apresentam, portanto, baixa taxa de crescimento do PIB per capita, e seus vizinhos têm características similares e estão localizados nos municípios de Bom Jesus de Goiás, Castelândia, Cromínia, Inaciolândia, Mairipotaba, Maurilândia, Piracanjuba, Pontalina, Porteirão, Quirinópolis, Santa Helena de Goiás, Turvelândia, Varjão, Nova Roma, Itajá e Rio Verde. 
No cluster BA, em cor azul claro, estão os dezesseis municípios com baixo crescimento próximos daqueles com altas taxas de crescimento (são eles: Campos Verdes, Nova Iguaçu de Goiás, Pilar de Goiás, Teresina de Goiás, Mara Rosa, São Simão, Ouvidor e Campo Limpo de Goiás) que apresentaram pequena elevação na taxa de crescimento do PIB per capita no período e anual de 3,0\% e 0,33\% a.a., respectivamente. No quarto cluster $\mathrm{AB}$, em cor rosa, estão os quatro municípios com alta taxa de crescimento circunvizinhos daqueles com baixo crescimento (são eles: Aparecida de Goiânia, Edeia, Santo Antônio da Barra e Caçu) que apresentaram para o período supracitado as maiores taxas de crescimento de $72,85 \%$ e $6,27 \%$ a.a.

Ao analisar o período 2010-2016 (mapa 1B), os clusters AA apresentam taxas de crescimento do PIB per capita de 13,96\% e 1,88\% a.a., bem acima da média do estado de Goiás, 4,90\% e 0,69\%, com valores estatisticamente significativos (apêndice A, mapa A.1B). No entanto, as taxas de crescimento para o período permaneceram abaixo, comparadas ao período de 2002 a 2010.

MAPA 1

Mapa de clusters (LISA) da taxa de crescimento do PIB per capita - Goiás (2002-2010 e 2010-2016)

$3 A-2002-2010$

3B - 2010-2016
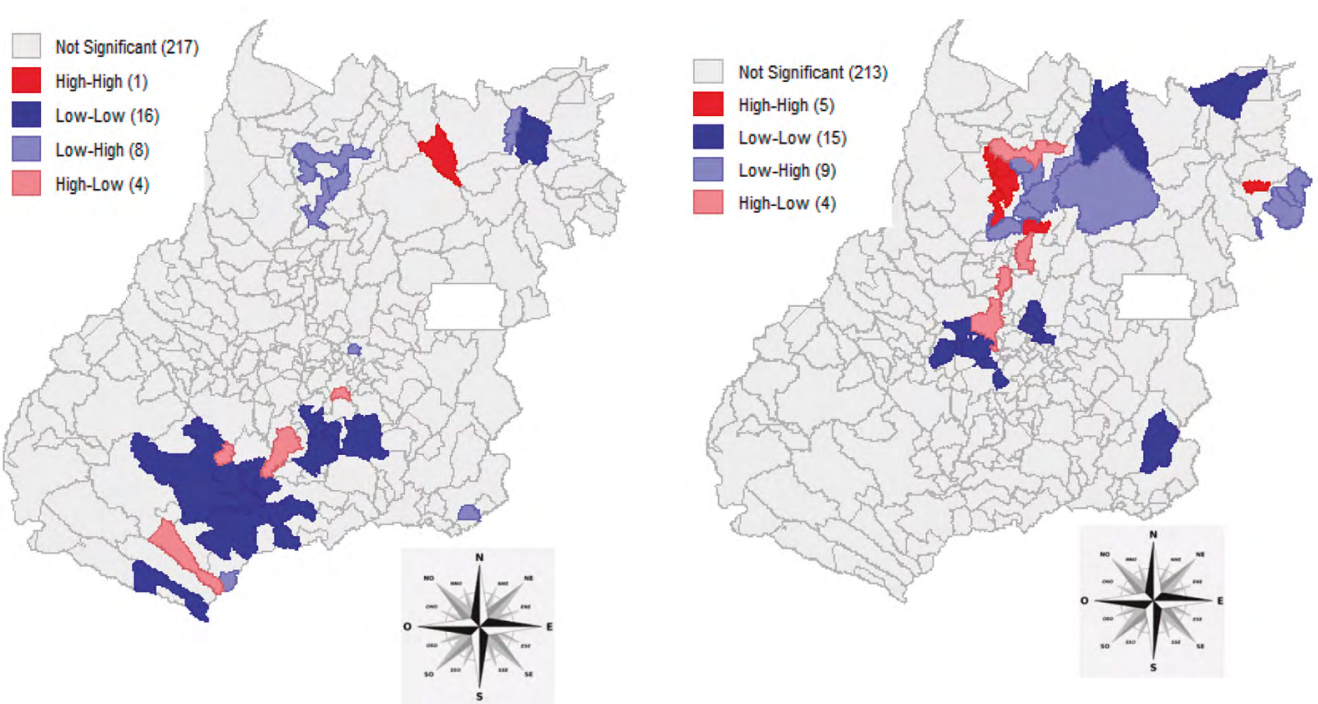

Fonte: Resultados da pesquisa.

Obs.: A pseudossignificância empirica é baseada em 999 permutações aleatórias. Nivel de significância de 0,05. 
Além disso, nesse período, o número de munícipios pertencentes aos clusters AA passou de um para cinco. Os municípios estáo localizados nas regiôes norte e nordeste e são eles: Guarinos, São Luiz do Norte, Simolândia, Campos Verdes e Santa Terezinha de Goiás.

Ao analisar o processo de disparidades econômicas geograficamente, pode-se afirmar que nos clusters AA existem tendências de maior percentual de crescimento econômico, haja vista que são municípios de baixo dinamismo econômico e que estariam em regiôes mais pobres, comparadas às regióes de maior dinamismo e de melhor localização.

Por outro lado, no período de 2010 a 2016, comparado ao período anterior, houve uma pequena redução no número de municípios com baixas taxas de crescimento no cluster $\mathrm{BB}$, de dezesseis para quinze. Ademais, nesse período houve considerável queda da taxa média de crescimento do PIB per capita, de $-5,80 \%$, e da taxa média anual de crescimento, de $-0,85 \%$ a.a., no período analisado. Nos clusters BA, o número de municípios passou de oito para nove no período 2010-2016 e foi apresentada queda de $-4,29 \%$ na taxa de crescimento médio e de $-0,62 \%$ a.a., são eles: Damianópolis, Hidrolina, Itapaci, Sítio d'Abadia, Alto Horizonte, Mambaí, Niquelândia, Nova Iguaçu de Goiás e Uruaçu. Entretanto, nos clusters AB, os municípios de Itaberaí, Santa Isabel, Uruana e Mara Rosa apresentaram, no mesmo período, considerável taxa média de crescimento, $15,97 \%$ e $2,14 \%$ a.a.

Em suma, ao analisar os períodos 2002-2010 e 2010-2016 por meio da estatística espacial, é possível confirmar a hipótese das premissas teóricas de Perroux, Myrdal e Hirschman de que o crescimento econômico não ocorre de forma homogênea no espaço e no tempo, haja vista que as decisóes de investimento em Goiás têm se concentrado nos municípios de maior dinamismo econômico, ocasionando de forma heterogênea um crescimento desigual e desequilibrado nos espaços regionais, ao mesmo tempo em que resulta na concentração da atividade econômica em determinados municípios com a continuidade desse cenário.

Portanto, por meio da análise LISA, é possível afirmar que não existe dependência/ associação espacial para a taxa de crescimento do PIB per capita. Ao dividir o período em dois momentos, o período de 2010 a 2016 apresentou maior quantidade de municípios no clusters AA, e também maior taxa de crescimento do PIB per capita para os municípios do cluster $\mathrm{BB}$. 
Pode-se afirmar que os municípios de maiores/menores taxas são contíguos de municípios com as mesmas características. Conclui-se que a localização influencia diretamente no crescimento econômico municipal, conforme os mapas mostraram os municípios supracitados. O trabalho em questão apresenta e corrobora resultados muito semelhantes aos encontrados por Barreto et al. (2010), Dassow, Costa e Figueiredo (2012) e Lima e Lima (2016).

\subsection{Clusters do PIB per capita}

$\mathrm{Na}$ análise dos clusters do PIB per capita municipal para os anos 2002, 2010 e 2016, houve algumas alteraçóes na composição dos municípios que compóem tais clusters nestes três anos. A análise LISA revela valores estatisticamente significativos para os clusters AA e BB (apêndice A, mapa A.2) por se tratar dos municípios no estado que tiveram características similares/dissimilares de crescimento/queda do PIB per capita no período supracitado.

Como é destacado no mapa 2A, no ano de 2002, observa-se que doze municípios apresentaram a classificação no cluster AA e encontram-se espalhados na porção centro-sul do estado de Goiás, especialmente, concentrados na regiáo do sudoeste de Goiás. Foram classificados como BB, 28 municípios com uma concentração na porção centro-norte de Goiás, com destaque para as regiōes central, nordeste e noroeste. Desse modo, o mapa 2A destaca que o produto goiano está localizado nas microrregióes do sul do estado, em detrimento a regiáo norte que concentra grande parte dos municípios com baixo crescimento econômico.

MAPA 2

Mapa de clusters (LISA) do PIB per capita - Goiás (2002, 2010 e 2016)

$4 \mathrm{~A}-2002$

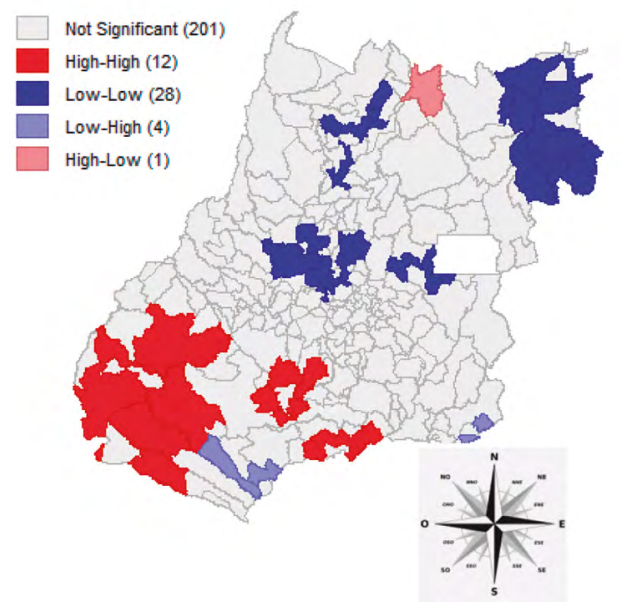

$4 \mathrm{~B}-2010$

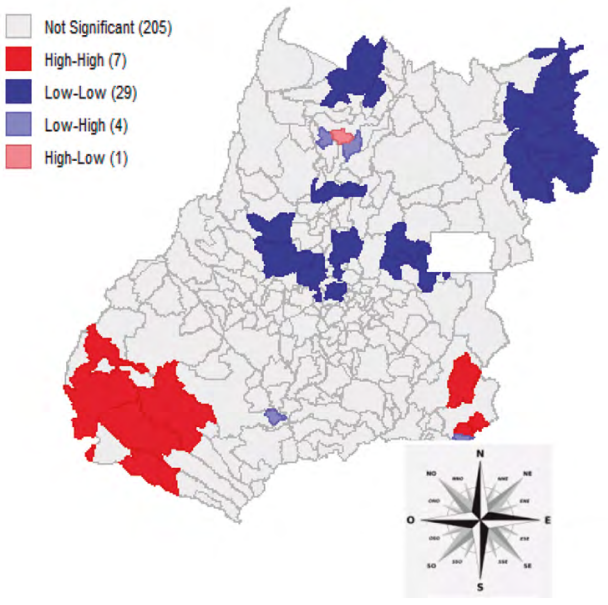




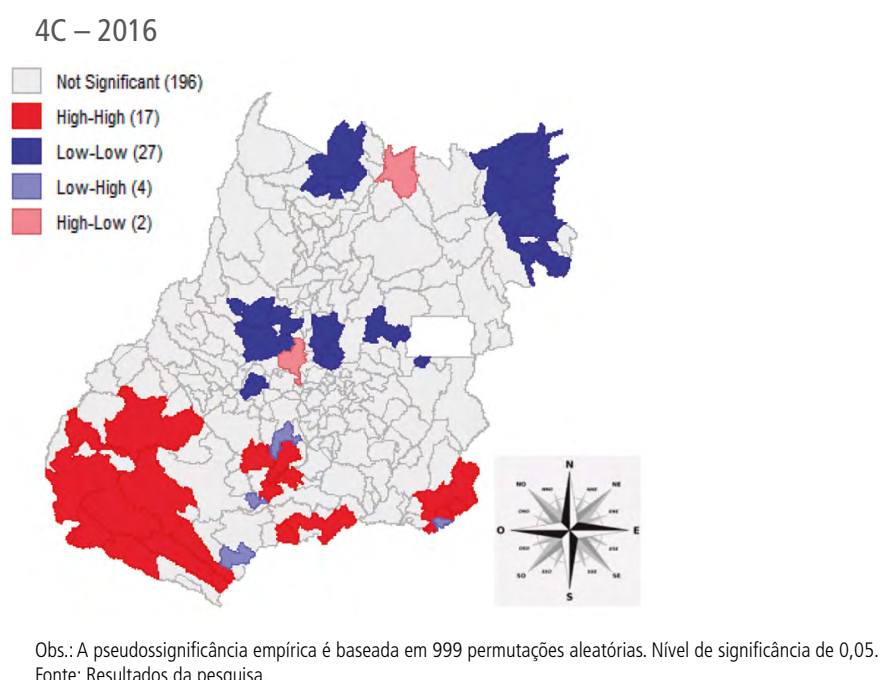
Fonte: Resultados da pesquisa.

No caso de 2010 (mapa 2B), observa-se que a mancha dos municípios que apresentaram a classificação AA passa de doze para sete e mantém-se nos municípios localizados na região do sudeste goiano. Em contraposição, constata-se que os municípios classificados em BB apresentaram pequena elevação, de 28 para 29, e estão localizados na regiāo centro-norte do estado de Goiás. Isto mostra claramente que, mesmo apresentando uma concentração da riqueza em alguns municípios goianos, ainda assim, observa-se uma ligeira redução nos municípios pobres quando comparado com o ano de 2002.

Em 2016 (mapa 2C), observa-se, por um lado, que os municípios classificados em AA aumentaram para dezessete em relação a 2010, embora mantivessem espalhados em quatro manchas bem definidas na mesorregião do Sul Goiano, na qual estão localizadas as microrregióes do sudoeste de Goiás: Quirinópolis, Meia Ponte, Vale do Rio dos Bois e Catalão. Nestas microrregióes, a presença de atividades econômicas está bastante integrada às cadeias e complexos agroindustriais de grãos, carnes, alimentos, adubos e fertilizantes, mineração e automóveis, o que influencia diretamente a majoração dos PIBs per capita no período analisado.

Por outro lado, há uma estabilidade no número de municípios classificados em BB, passando de 29 para 27, os quais se concentraram em cinco manchas localizadas nas regióes centro-norte, noroeste e norte do estado. Isto posto, verifica-se que esta análise corrobora o trabalho de Lima e Lima (2016), que defende a existência de um processo de concentração de riqueza na regiāo centro-sul de Goiás, vis-à-vis a estagnação e manutenção da pobreza na regiáo centro-norte do estado quando comparado com o ano de 2010 e, consequentemente, a continuidade da situação de baixo crescimento do PIB per capita. 
Portanto, para os anos de 2002, 2010 e 2016, observa-se que os clusters BB apresentaram características de baixo PIB per capita e sáo contíguos de municípios com as mesmas características. Estes estão localizados, principalmente nas microrregióes de Porangatu, Rio Vermelho, Iporá, entorno de Brasília, Ceres, Chapada dos Veadeiros e Vão do Paranã. Os municípios padecem, portanto, de um mesmo problema: a continuidade dos baixos PIBs per capita ao longo dos anos. Ou seja, municípios que têm apresentado, historicamente, baixos níveis de dinamismo econômico e pífio PIB per capita, também padecem de problemas socioeconômicos como a desigualdade social e regional, o baixo crescimento econômico, sendo premente a criação e a elaboração de políticas públicas eficientes para o desenvolvimento inter-regional no estado de Goiás.

Os desequilíbrios intrarregionais se objetivaram, em especial, em decorrência do hiato existente entre os municípios classificados em $\mathrm{AA}$ e $\mathrm{BB}$, os quais se cristalizaram em virtude do processo histórico de formaçáo econômica do estado de Goiás. Desde os anos 1930, o vetor interno de integraçáo do mercado goiano ao mercado do Sudeste, em especial, do estado de São Paulo, centro econômico nacional, foi se constituindo em meio a "Marcha para o Oeste", que teve um papel fundamental para acelerar o processo de modernização conservadora das estruturas produtivas goianas a partir de meados dos anos 1960.

Com o avanço da modernizaçáo da agricultura, a produçáo agrícola goiana se expande, em especial, a partir dos anos 1980, com a entrada das principais tradings companies, que criaram, em conjunto com o Estado, as condiçóes objetivas para a expansão agrícola e crescimento industrial de Goiás.

Tais avanços se intensificaram a partir dos anos 1990, com a conexão do estado de Goiás aos Enid que tiveram um papel singular na integração desse espaço regional aos mercados internacionais. Assim, Samuel (2008, p. 23) destacou que as “(...) grandes agroindustriais e tradings mundiais passaram a ocupar gradativamente o espaço deixado pelo Estado e começaram a financiar as produçóes agrícolas mais lucrativas e com grandes nichos de mercado, como no caso da soja".

Este fato teve um papel singular no desenvolvimento do espaço territorial da regiáo centro-sul do estado de Goiás, pois, impulsionado pela agricultura científica globalizada, criou uma

(...) nova forma de organização do agronegócio brasileiro, emergente na década de 1990, caracterizada principalmente pela incorporação das novas tecnologias da informaçâo ao campo e pela menor intervenção estatal. Trata-se da transição de um período de forte intervenção estatal na agricultura, predominante desde a década de 1960, para uma maior regulação das empresas mundiais do comércio agrícola (tradings); e do aperfeiçoamento e uso mais intensivo dos insumos químicos, biológicos e mecânicos difundidos pelo paradigma da Revolução Verde (Samuel, 2013, p. 2). 
Desse modo, a produção agrícola e industrial se expande pelo território goiano reforçando, assim, os desequilíbrios intrarregionais. Quer dizer, nos clusters $\mathrm{BA}$ e AB, prevalecem os municípios com baixos/altos PIBs per capita localizados próximos de municípios com altos/baixos PIBs per capita. Em 2002, 2010 e 2016, no cluster BA constam os municípios de Paranaiguara, Caçu, Indiara, Três Ranchos, Maurilândia e Davinópolis; no cluster $\mathrm{AB}$, estão os municípios de Minaçu, Alto Horizonte e Itaberaí.

Em suma, baseado na análise da estatística espacial, tanto para os clusters espaciais da taxa de crescimento do PIB per capita quanto para os clusters espaciais do próprio PIB per capita, os resultados convergem na identificaçáo de tais clusters espaciais para os anos de 2002, 2010 e 2016, revelando claramente que há um padrão de distribuição espacial municipal bastante heterogêneo e desigual do PIB per capita no estado. Quer dizer, há uma forte heterogeneidade estrutural e produtiva no estado de Goiás, a qual reforça um padrão de modernizaçáo econômica na regiáo centro-sul do estado em detrimento da regiáo centro-norte. Especificamente, observa-se uma concentração da atividade econômica nos municípios localizados, mormente, na mesorregião do Sul Goiano, em detrimento aos municípios localizados nas mesorregióes do Leste Goiano, do Centro Goiano, do Norte Goiano e do Noroeste Goiano.

\section{CONSIDERAÇÕES FINAIS}

O objetivo deste trabalho foi identificar em que medida o crescimento econômico observado no estado de Goiás determinou o padrão de distribuição espacial do PIB per capita dos municípios goianos nos anos de 2002, 2010 e 2016, ao considerar a dependência e a associação espacial dos municípios. A hipótese do trabalho baseia-se nas premissas teóricas de Myrdal (1965), Perroux (1977) e Hirschman (1977) de que o processo de crescimento econômico não ocorre de forma homogênea no espaço e no tempo, mas bastante heterogêneo no espaço regional ocasionando, assim, um crescimento desequilibrado entre os espaços regionais.

Os resultados dos diagramas de dispersão do índice de Moran global, anos 2002, 2010 e 2016, para as variáveis supracitadas são de que existe dependência espacial nos municípios, ou seja, a localizaçáo tende a influenciar o PIB per capita, embora não tenha apresentado autocorrelação espacial para as taxas de crescimento do PIB per capita. Para o primeiro caso, observa-que os municípios com altos/baixos valores (PIB per capita) apresentam contiguidade também com outros municípios com altos/baixos valores, 
embora a maioria esteja localizada no terceiro quadrante BB. Isso significa que a maior parte dos municípios goianos apresenta baixo PIB per capita (BB) e estes são circunvizinhos de outros municípios com as mesmas características, apesar da ligeira melhora (primeiro quadrante AA) nos anos 2002 e 2016.

Os clusters AA do PIB per capita revelam que municípios com altas/baixas taxas de crescimento são contíguos, sendo também vizinhos de municípios com as mesmas características e estatisticamente significativos. Ademais, as taxas de crescimento para o PIB per capita estão acima da média do estado de Goiás, para os municípios localizados, principalmente na mesorregiáo Sul Goiano, dos quais pertencem as microrregióes do sudoeste de Goiás: Quirinópolis, Meia Ponte, Vale do Rio dos Bois e Catalão. A forte integração das atividades econômicas das cadeias e dos complexos agroindustriais de grãos, carnes, alimentos, adubos e fertilizantes, mineração e automóveis favorece a manutençáo do PIB per capita elevado no período analisado.

Entretanto, os clusters BB têm taxas abaixo da média do estado de Goiás e têm se localizado principalmente nas microrregióes de Porangatu, Rio Vermelho, Iporá, entorno de Brasília, Ceres, Vão do Paranã, Anicuns, Anápolis e Chapada dos Veadeiros. Nestas microrregióes, as principais atividades econômicas de menor integração, consideradas de baixa taxa de crescimento econômico, são: administração, saúde e segurança públicas, turismo, cerâmica, pecuária leiteira e agricultura.

Um dos grandes problemas regionais nestas regiôes é a ausência de infraestrutura básica do estado na promoção de políticas públicas em parceria com a iniciativa privada na atraçáo de novos investimentos produtivos para a geração de emprego e renda. Os governos federal e estadual têm promovido, através de programas de desenvolvimento regional, a utilização de recursos de fundos constitucionais, como é o caso do BNDES e do FCO, mas ainda não têm alcançado os resultados esperados de redução das assimetrias regionais, aliás, o que se observa é a elevação das disparidades entre as regiôes ricas e pobres.

Portanto, os resultados do trabalho baseados na Aede, principalmente dos clusters espaciais locais (AA e BB), tendem a corroborar a hipótese baseada nas teorias de Perroux, Myrdal e Hirschman acerca das premissas do crescimento desequilibrado, pela existência de polos de aglomeração e de concentração de investimentos em determinados municípios, puxados pelas indústrias motrizes e indústrias-chave, correlatas e secundárias, as quais estão reforçando a concentração da atividade econômica em espaços específicos do território goiano, em especial, na região centro-sul do estado. 
Pode-se afirmar que em Goiás há um padrão de distribuição do PIB per capita bastante heterogêneo, seja no espaço ou seja no tempo, que resulta no fortalecimento dos desequilíbrios regionais, necessitando, portanto, da atuação do estado na elaboração de políticas públicas que tenham por fito minimizar as distorçôes de distribuição assimétrica dos investimentos produtivos no espaço regional goiano.

Isso pode acontecer por meio do direcionamento do estado de um conjunto de investimentos públicos ou, em parceria com a iniciativa privada, que tenha por objetivo construir um tecido industrial mais homogêneo entre as regióes, sobretudo, estimulando efeitos de encadeamento e agregaçáo de valor nas cadeias produtivas locais. Para tanto, se faz necessário construir um projeto claro para o estado no sentido de tecer cenários consistentes de curto, médio e longo prazos, com objetivos e metas bem delineadas e aderentes à realidade dos agentes econômicos locais envolvidos no processo de industrialização do estado.

Tudo isto teria um papel fundamental para corrigir uma distorção do estilo de desenvolvimento do estado que, no atual momento, reforça um padrão de concentraçáo de investimentos em atividades econômicas existentes, principalmente nos municípios localizados na mesorregião centro-sul de Goiás, em detrimento aos municípios localizados nas mesorregióes do centro-norte goiano.

\section{REFERÊNCIAS}

ALMEIDA, E. S. Econometria espacial aplicada. Campinas: Alínea Editora, 2012.

ANSELIN, L. Local Indicators of Spatial Association - LISA. Geographical Analysis, v. 27, n. 2, p. 93-115, 1995. Disponível em: <https://bit.ly/3caDsaY>. Acesso em: 9 nov. 2015.

. Local Indicators of Spatial Association - LISA. Spatial Econometrics. In: BALTAGI, B. H. A companion to theoretical econometrics. Hoboken: Wiley-Blackwell, 2003. Disponível em: <https://bit.ly/2OCb8WO>. Acesso em: 8 out. 2019.

ARRIEL, M. F. A dinâmica produtiva e espacial da indústria goiana. 2017. 207 f. Tese (Doutorado) - Universidade Federal de Goiás, Instituto de Estudos Socioambientais (IESA), Goiânia, 2017. Disponível em: <https://bit.ly/3enu0Ul>. Acesso em:10 nov. 2019.

BACCHI, M. R. P; CALDARELLI, C. Impactos socioeconômicos da expansão do setor sucroenergético no Estado de São Paulo entre 2005 e 2009. Nova Economia, Belo Horizonte, v. 25, n. 1, jan./abr. 2015. Disponível em: <https://bit.ly/30vz0xS>. Acesso em: 10 set. 2019. 
BARRETO, R. C. S.; ALMEIDA, E. S.; LIMA, J. E. Convergência espacial do PIB per capita no estado do Ceará. Revista de Economia, v. 36, n. 3 p. 25-40, set./dez. 2010. Disponível em: <https://bit.ly/3btklK8>. Acesso em: 12 nov. 2019.

BASTOS, C. P.; BRITTO, G. Introdução à economia do subdesenvolvimento. In: ARGAWALA, A. N.; SINGH, S. P. (Coords.). A Economia do Subdesenvolvimento. Rio de Janeiro: Ed. Contraponto, 2010.

CÂMARA, G. et al. Análise espacial de áreas. In: FUCKS, S. D. et al. Análise espacial de dados geográficos. São Jose dos Campos: Inpe, 2002. Disponível em: <https://bit.ly/311T9VL>. Acesso em: 25 mar. 2020.

CASTRO, A. C.; FONSECA, M. G. A dinâmica agroindustrial do Centro-Oeste. Brasília: Ipea, 1995.

DASSOW, C.; COSTA, R. M. G. S.; FIGUEIREDO, A. M. R. Crescimento econômico e clusters municipais no estado de Mato Grosso. Nexus Econômicos, v. VI, n. 10, jun. 2012. Disponível em: <https://bit.ly/2N5ArAi>. Acesso em: 7 out. 2019.

FURTADO, C. Desenvolvimento e subdesenvolvimento. Rio de Janeiro: Fundo de Cultura, 1964.

HIRSCHMAN, A. Transmissão inter-regional do crescimento econômico. In: SCHWARTZMAN, S. (Org.). Economia regional: textos escolhidos. Belo Horizonte, CEDEPLAR, 1977.

IBGE - INSTITUTO BRASILEIRO DE GEOGRAFIA E ESTATÍSTICA. Cidades. IBGE, [s.d.]. Disponível em: <https://bit.ly/3eoEAuj>. Acesso em: 10 nov. 2019.

. Produto Interno Bruto dos Municípios 2018. IBGE, [s.d.]. Disponível em: <https://bit.ly/3sXJLFw>. Acesso em: 10 nov. 2019.

IPEA - INSTITUTO DE PESQUISA ECONÔMICA APLICADA. Contas nacionais. Ipea, [s.d.]. Disponível em: <https://bit.ly/3kYl4pC> Acesso em: 12 nov. 2019.

IMB - INSTITUTO MAURO BORGES. Goiás em Dados. IMB, 2018. Disponível em: <https://bit.ly/310HZ3V>. Acesso em: 10 nov. 2019.

LIMA, R. C. A.; LIMA, J. P. R. Distribuição do PIB per capita nas microrregiōes brasileiras: uma análise exploratória espacial. Planejamento e Políticas Públicas, n. 47, jul./dez. 2016. Disponível em: <https://bit.ly/3vbGdSb>. Acesso em: 12 nov. 2019.

MYRDAL, G. Teoria econômica e regióes subdesenvolvidas. Rio de Janeiro: Saga, 1965.

PERROUX, F. O conceito de pólo de crescimento. In: SHWARTZMAN, J. (Org.). Economia regional: textos escolhidos. Belo Horizonte: Cedeplar, 1977.

PIRES, M. J. S. As implicaçóes do processo de modernizaçáo conservadora na estrutura e nas atividades agropecuárias da regiáo centro-sul de Goiás. 2008. 146 f. Tese (Doutorado) - Instituto de Economia, Universidade Estadual de Campinas, São Paulo, 2008. 
Uma sistematizaçáo da discussáo sobre heterogeneidade industrial. um olhar para além das regiôes brasileiras: o caso do Centro-Oeste brasileiro. Brasília: Ipea, 2016. (Texto para Discussão, n. 2257).

ROSTOW, W. W. A decolagem para o crescimento autossustentado. In: AGARWALA, A. N.; SINGH, S. P. (Eds.). A economia do subdesenvolvimento. Rio de Janeiro: Contraponto, 2010. p. 406-456.

SAMUEL, F. Agricultura científica globalizada e fronteira agrícola moderna no Brasil. Confins, n. 17, 2013. Disponível em: <https://bit.ly/3cf0Jsh>.

Território, capital financeiro e agricultura Land Grabbing e fronteira agrícola no Brasil. 2018. Tese (Livre Docência) - Instituto de Geociências e Ciências Exatas, Universidade Estadual Paulista Júlio de Mesquita Filho, Rio Claro, 2018.

SATO, R. The harrod-domar model vs the neo-classical growth model. The Economic Journal, v. 74, n. 294, p. 380-387, 1964. Disponível em: <https://bit.ly/3epDjmK>. Acesso em: 12 nov. 2019.

SCRUCCA, L. Clustering multivariate Spatial Data based on Local Measures of Spatial Autocorrelation: An application to the labour market of Umbria. Perugia: Università degli Studi di Perugia, 2005. Disponível: <https://bit.ly/38ocfAx>. Acesso em: 20 out. 2019.

SILVA, G. J.; SOUZA, E. C; MARTINS, H. E. P. Produção agropecuária em municípios de Minas Gerais (1996-2006): padrões de distribuição, especialização e associação espacial. RESR, Piracicaba, v. 50, n. 2, p. 333-350, abr./jun. 2012. Disponível em: <https://bit.ly/3caHDDG>. Acesso em: 5 out. 2019.

SOUZA, N. J. Desenvolvimento econômico. 4. ed. São Paulo: Atlas, 1999.

VIEIRA, R. S. Crescimento econômico no estado de Sáo Paulo: uma análise espacial. São Paulo: Editora Unesp; Cultura Acadêmica, 2009. Disponível em: <https://bit.ly/2Ox5PYJ>. Acesso em: 29 out. 2019.

\section{BIBILIOGRAFIA COMPLEMENTAR}

PIRES, M.J.S. Estratégia de transformação econômica do Centro-Oeste: o caminho externo. Rio de Janeiro: Ipea, 2019. (Texto para Discussão, n. 2504). 


\section{APÊNDICE A}

MAPA A.1

Mapa de significância da taxa de crescimento do PIB per capita - Goiás (2002-2010 e 2010-2016)

A.1A - 2002 a 2010

A.1B -2010 a 2016
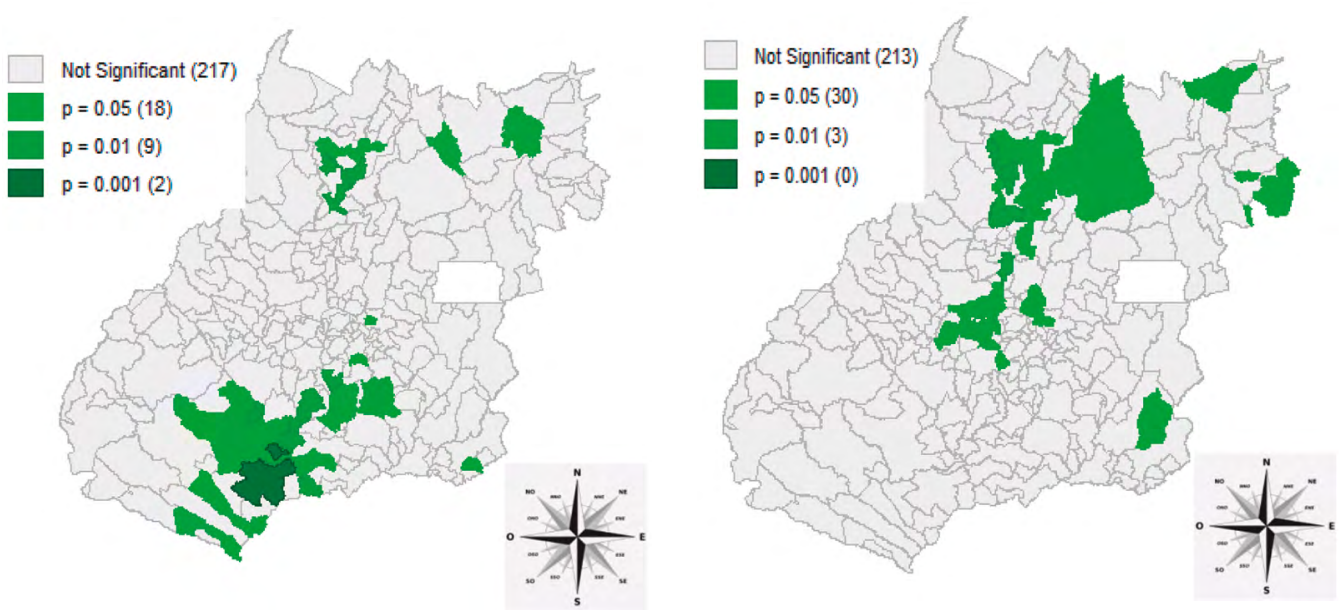

Fonte: Resultados da pesquisa.

Obs.: A pseudossignificância empírica é baseada em 999 permutações aleatórias. Nível de significância de 0,05.

MAPA A.2

Mapa de significância do PIB per capita - Goiás (2002, 2010 e 2016)

A. $2 \mathrm{~A}-2002$

A. $2 B-2010$
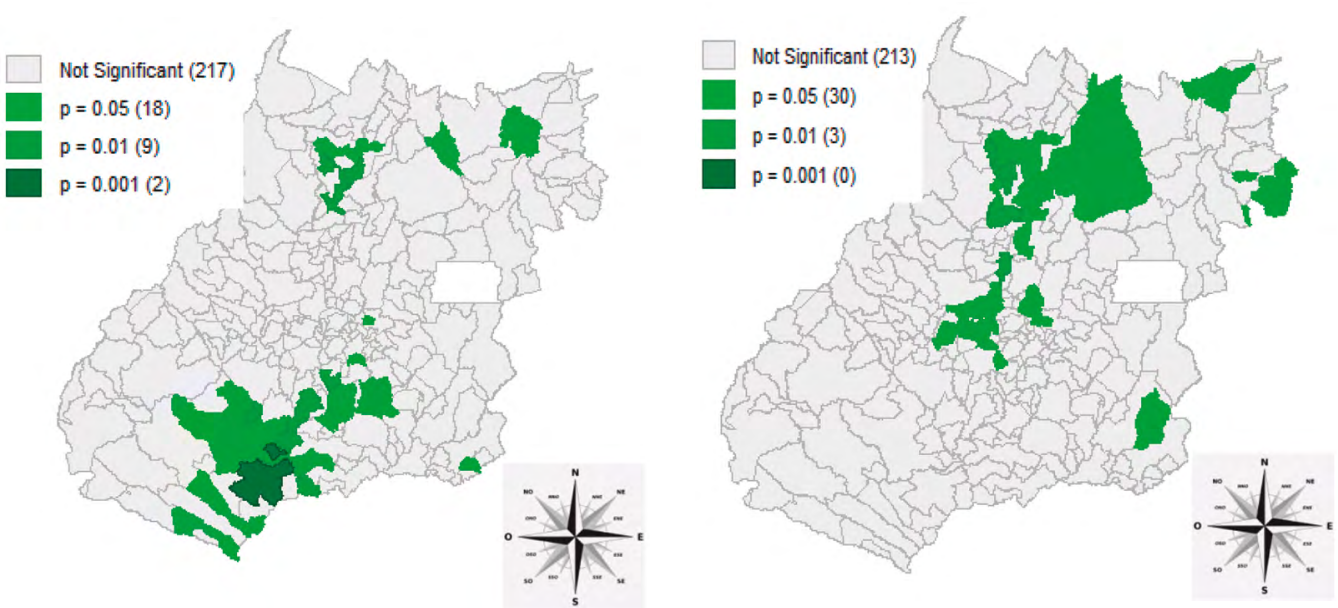
Texto para

Discussão

2636 Crescimento Econômico e a Associação Espacial de Clusters Municipais no Estado de Goiás: 2002-2016

A.2C -2016

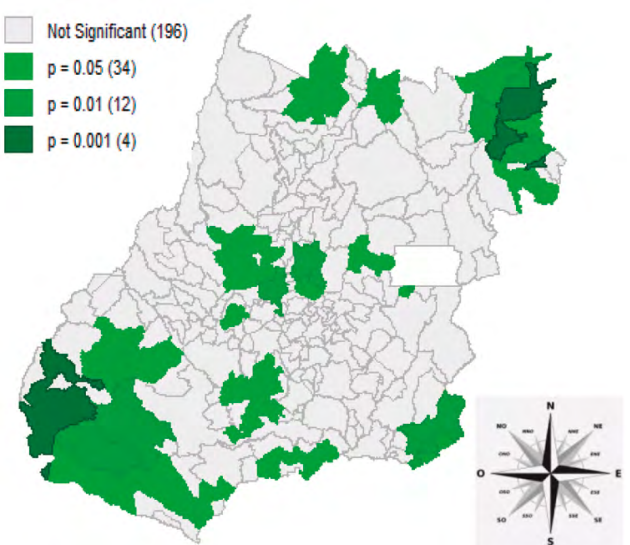

Fonte: Resultados da pesquisa.

Obs.: A pseudossignificância empírica é baseada em 999 permutações aleatórias. Nivel de significância de 0,05. 


\section{APÊNDICE B}

\section{NOTAS METODOLÓGICAS}

O PIB per capita municipal foi deflacionado pelo deflator implícito, oriundo da divisão no (numerador), do cálculo da variaçáo do $\mathrm{VAB}$ do estado de Goiás entre os períodos de 2002 a 2010 e de 2010 a 2016; e no (denominador), do cálculo da variação do Índice de Volume de Goiás para os períodos supracitados - equaçóes B.1 e B.2). Os dados foram obtidos das Contas Regionais do Instituto Brasileiro de Geografia e Estatística (IBGE).

$$
\begin{aligned}
& D e f_{2010 / 2002}=\left(\frac{V a d b_{2010}}{V a d b_{2002}}\right) /\left(\frac{\text { Ivol }_{2010}}{\operatorname{Ivol}_{2002}}\right) \text {, } \\
& D e f_{2016 / 2010}=\left(\frac{V a d b_{2016}}{V a d b_{2010}}\right) /\left(\frac{\text { Ivol }_{2016}}{\operatorname{Vvol}_{2010}}\right) \text {, }
\end{aligned}
$$

onde Vadb é o VAB dos anos 2002, 2010 e 2016 para o estado de Goiás; Ivol é o índice de volume dos mesmos anos; e o Defé o deflator que é a razão da variação do Vadb e da variação do Ivol para o período supracitado. Multiplicou-se o PIB per capita municipal dos anos iniciais (valores correntes) de cada período pelo deflator tem-se o PIB per capita a preços constantes. Posteriormente, dividiu-se o PIB per capita dos anos finais de cada período pelos valores obtidos do resultado anterior. A razão do PIB per capita a preços correntes pelo PIB per capita a preços constantes resulta na variação percentual da taxa de crescimento do PIB per capita (2002-2010) e (2010-2016). 

Ipea - Instituto de Pesquisa Econômica Aplicada

Assessoria de Imprensa e Comunicação

EDITORIAL

\section{Chefe do Editorial}

Reginaldo da Silva Domingos

\section{Assistentes da Chefia}

Rafael Augusto Ferreira Cardoso

Samuel Elias de Souza

\section{Supervisão}

Camilla de Miranda Mariath Gomes

Everson da Silva Moura

\section{Editoração}

Aeromilson Trajano de Mesquita

Anderson Silva Reis

Cristiano Ferreira de Araújo

Danilo Leite de Macedo Tavares

Jeovah Herculano Szervinsk Junior

Leonardo Hideki Higa

\section{Capa}

Danielle de Oliveira Ayres

Flaviane Dias de Sant'ana

\section{Projeto Gráfico}

Renato Rodrigues Bueno

The manuscripts in languages other than Portuguese published herein have not been proofread.

\section{Livraria Ipea}

SBS - Quadra 1 - Bloco J - Ed. BNDES, Térreo

70076-900 - Brasília - DF

Tel.: (61) 2026-5336

Correio eletrônico: livraria@ipea.gov.br 

Composto em adobe garamond pro 12/16 (texto) Frutiger 67 bold condensed (títulos, gráficos e tabelas) Brasília-DF 



\section{Missão do Ipea}

Aprimorar as políticas públicas essenciais ao desenvolvimento brasileiro por meio da produção e disseminação de conhecimentos e da assessoria ao Estado nas suas decisões estratégicas.

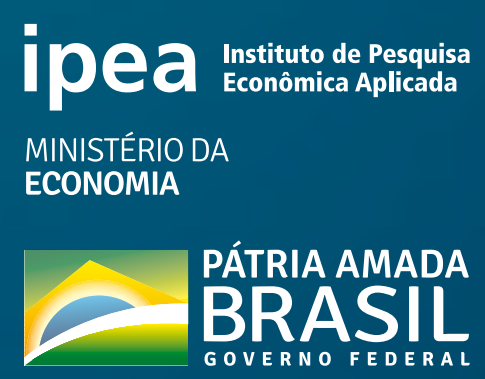

